\title{
Suppressive Effects of Fucoxanthin on Degranulation in IgE-antigen complex-stimulated RBL-2H3 Cells
}

\author{
Seung Namkoong ${ }^{1}$, Haemi Joo ${ }^{2}$, Seon-A Jang ${ }^{2}$, Ye-Jin Kim³ ${ }^{3}$ Taeseong Kim³ and Eun-Hwa Sohn ${ }^{3 *}$ \\ ${ }^{1}$ Department of Physical Therapy, Kangwon National University, Samcheok 245-710, Korea \\ ${ }^{2}$ Radiation Health Research Institute, Korea Hydro \& Nuclear Power Co., Ltd, Seoul 132-703, Korea \\ ${ }^{3}$ Department of Herbal Medicine Resource, Kangwon National University, Samcheok 245-710, Korea
}

\begin{abstract}
The marine carotenoid fucoxanthin can be found in marine brown seaweeds, macroalgae, diatoms, and microalgae, and has remarkable biological properties. Numerous studies have shown that fucoxanthin has considerable potential and promising applications in human health, but the underlying mechanisms involved in its anti-allergic activity are not fully understood. We here investigated the mechanisms by anti-allergic activity of fucoxanthin fraction from Eisenia bicyclis in immunoglobulin E-antigen complex (IgE/DNP-BSA)-stimulated RBL-2H3 mast cells. This study we found that the fucoxanthin inhibits the release of $\beta$-hexosaminidase and suppressed not only transcriptional activation of NF- $\kappa \mathrm{B}$, but also phosphorylation of ERK and JNK in IgE/DNP-BSA-treated RBL-2H3 cells. Fucoxanthin may be useful for preventing allergic diseases, including asthma and atopic dermatitis.
\end{abstract}

Key words - Allergy, $\beta$-Hexosaminidase, MAPK, NF-кB

\section{Introduction}

Mast cells and basophils play important roles initiating and perpetuating the inflammatory responses that mediate allergic reactions by secreting abundant levels of proinflammatory mediators such as histamine and several cytokines, including interleukin (IL)-4, IL-5, IL-13, and tumor necrosis factor (TNF)-a (Matsuda et al., 2008). Because mast cells play essential roles in provoking the pathogenesis of allergic reactions via the degranulation process, measuring the degree of degranulation reflects the level of mast cell activation. $\beta$ -Hexosaminidase released by these cells during this process has been reported to be a suitable marker for determining the degree of degranulation (Naal et al., 2004). The rat basophilic leukemia cell line RBL-2H3, which expresses FceRI, is widely used to study the molecular basis of mast cell activation (Huang et al., 2008). This cell line has also been used to develop anti-allergy drugs that reduce allergic symptoms, including steroids that have anti-histamine actions and antiinflammatory drugs that inhibit cytokine production (Matsuda et al., 2008; Huang et al., 2008). However, the effectiveness

${ }^{*}$ Corresponding author. E-mail : ehson@kangwon.ac.kr of such drugs is limited by their side effects. These problems have led to increasing interest in traditional herbal medicines that have been used to treat allergic diseases. As a result, more and more studies examining the efficacy of natural extracts and compounds isolated from natural extracts to prevent and treat allergic disorders are being performed.

Marine environment has been the source of diverse life forms that produce different biologically active compounds. Metabolites from marine plants have been reported to have outstanding biological activities and profound applications in nutraceuticals, cosmeceuticals, and pharmaceuticals. Eisenia bicyclis is a species of the kelp, a member of the brown algae group of seaweeds, best known for its use in Asia. E. bicyclis is high in calcium, iodine, iron, magnesium, and vitamin A as well as being a good dietary source for many other minerals. They also contain the storage polysaccharide laminarin, alginate, fucoxanthin and fucoidan with immunological activities (Joe et al., 2006). It has been also known that brown algae extracts closely linked to its protective properties against free radical attack and have anti-oxidant, immunomodulatory effects $\mathrm{CH}$ et al., 2010; Kang et al., 2004; Namkoong et al., 2011) and numerous studies have shown that fucoxanthin has considerable potential and promising applications in human health (Peng 


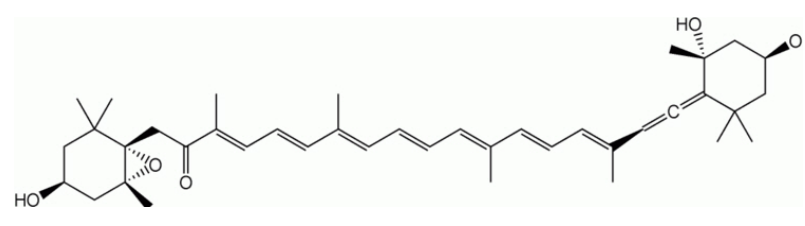

Fig. 1. Structure of fucoxanthin.

et al., 2011).

Although E. bicyclis and its component, fucoxanthin have these biological activities, no reported study has evaluated the anti-allergic effect of E. bicyclis or fucoxanthin and the molecular mechanisms involved. Therefore, we examined the fucoxanthin (Fig. 1) isolated from E. bicyclis on the antiallergic effects by checking the release of $\beta$-hexosaminidase induced by IgE/DNP-BSA in RBL-2H3 mast cells and the molecular mechanisms such as MAPKs-NF- $\mathrm{KB}$ activities, which are activated during allergic inflammation.

\section{Materials and Methods}

\section{Preparation of fucoxanthin}

The fronds of Eisenia bicyclis were harvested from the coast of Ulleung Island, East Sea, South Korea in June 2009. Fresh E. bicyclis was washed three times with tap water to remove salt and impurities, then dried at room temperature for 3 days and stored at $-20^{\circ} \mathrm{C}$. The dried samples were homogenized, using a grinder, before extraction. The fucoxanthin fraction was prepared by solvent partition method from the acetone extract of fresh E. bicyclis. Fucoxanthin fraction was used for CPC (centrifugal partition chromatography) using a two-phase solvent system of n-hexane-ethyl acetate-ethanolwater $(5: 5: 7: 3, \mathrm{v} / \mathrm{v} / \mathrm{v} / \mathrm{v})$. The flow rate of mobile phase was 2 $\mathrm{ml} / \mathrm{min}$ with descending mode while rotating at $1000 \mathrm{rpm}$. The eluate was monitored at $410 \mathrm{~nm}$. The content and structure of fucoxanthin in the $\mathrm{CPC}$ fraction were confirmed with HPLC, UV, APCI/MS and NMR spectra. A preparative CPC yielded $20 \mathrm{mg}$ of fucoxanthin ( $87 \%$ recovery from fucoxanthin fraction) in a two-step separation from $516 \mathrm{mg}$ of fucoxanthin fraction containing $4.59 \%$ fucoxanthin. The purity of the isolated fucoxanthin was about $81 \%$ in the first CPC step and over $95 \%$ in the second CPC step based on the calibration curve. This fucoxanthin was kindly provided by Dr. Um (Natural Product Research Center, KIST Gangneung Institute, Korea)
(Kim et al., 2011).

\section{Cell culture}

The RBL-2H3 rat mast cell line, HaCaT human keratinocyte cell line, NIH3T3 mouse fibroblast cell line were obtained from the American Type Culture Collection (Rockville, MD) and grown in minimum essential medium (MEM) with 15\% fetal bovine serum (FBS), $2 \mathrm{mM}$ L-glutamine, $100 \mathrm{U} / \mathrm{ml}$ penicillin, and $100 \mu \mathrm{g} / \mathrm{ml}$ streptomycin at $37^{\circ} \mathrm{C}$ in a humidified incubator with a $5 \% \mathrm{CO}_{2} / 95 \%$ air atmosphere.

\section{Reagents}

The anti-dinitrophenyl (DNP)-IgE and 4-nitrophenyl Nacetyl- $\beta$-D-glucosaminide were from Sigma-Aldrich, DNPbovine serum albumin (BSA) was from Biosearch Technologies, minimum essential medium was from Invitrogen, fetal bovine serum (FBS) was from WelGENE, the protein assay kit was from BioRad Laboratories, anti-pERK, anti-ERK, anti-pJNK, anti-JNK, and anti-p-p38 were from Cell Signaling Technology, anti-p65 and anti-p38 were from Santa Cruz Biotechnology, anti- $\beta$-actin was from Sigma-Aldrich, anti- $\alpha$-tubulin was from Abfrontier, the ECL chemiluminescence system was from GE Healthcare, and the polyvinylidene difluoride (PVDF) membrane was from Millipore.

\section{XTT assay for cell survivability}

Cell survivability was examined using the XTT assay kit, according to the manufacturer's instructions. The spleen was removed aseptically and dissociated into a single cell suspension in culture medium. Cells $\left(5 \times 10^{5}\right.$ cells/well $)$ were incubated with various fucoxanthin concentrations $(0.1,1$, and $10 \mathrm{\mu g} / \mathrm{ml}$ ). After incubating the cells for $20 \mathrm{~h}$, a mixture of 25 $\mu 1$ of phenazine methosulfate (PMS; electron-coupling reagent) and $25 \mu l$ of XTT [2,3-bis(2-methoxy-4-nitro-5sulfophenyl)-2H-tetrazolium-5-carboxanilide] was added to each well. The cells were further incubated for $4 \mathrm{~h}$ to allow XTT formazan production. The absorbance was determined with a microplate reader at a test wavelength of $450 \mathrm{~nm}$ and a reference wavelength of $690 \mathrm{~nm}$.

\section{Nitrite determination}

Cells were incubated in either medium alone or medium 
supplemented for $24 \mathrm{~h}$ and the accumulation of nitrite in culture supernatants was measured using the assay system described by Ding et al. (1988). One hundred micro litter aliquots of culture supernatants were mixed with an equal volume of Griess reagent (mixture at 1:1 of naphthylethylenediamine dihydrochloride and $1 \%$ sulphanilamide in $5 \%$ $\mathrm{H}_{3} \mathrm{PO}_{4}$ ) and incubated at room temperature for $10 \mathrm{~min}$. Nitrite concentration was calculated from a $\mathrm{NaNO}_{2}$ standard curve.

\section{$\beta$-Hexosaminidase release assay}

Degranulation of RBL-2H3 cells was evaluated by measuring the activity of the granule-stored enzyme- $\beta$-hexosaminidase secreted in the extracellular medium. Cells were cultured in 24 -well plates $\left(2 \times 10^{5}\right.$ cells/well $)$ overnight. The cells were sensitized with anti-DNP-IgE $(100 \mathrm{ng} / \mathrm{ml})$ for $16 \mathrm{~h}$ at $37^{\circ} \mathrm{C}$. After washing the cells with TGCM buffer $(136 \mathrm{mM} \mathrm{NaCl}$, $2.68 \mathrm{mM} \mathrm{KCl}, 0.36 \mathrm{mM} \mathrm{NaH}{ }_{2} \mathrm{PO}_{2} \cdot \mathrm{H}_{2} \mathrm{O}, 1 \mathrm{mM} \mathrm{CaCl}_{2}, 0.5$ $\mathrm{mM} \mathrm{MgCl}_{2}, 11.9 \mathrm{mM} \mathrm{NaHCO}_{3}, 5 \mathrm{mM}$ dextrose, $1 \mathrm{~g} / \mathrm{L}$ gelatin, $\mathrm{pH} 7.4)$, they were pretreated with fucoxanthin $(0.1,1$, and 10 $\mu \mathrm{g} / \mathrm{ml})$ for $30 \mathrm{~min}$ and then treated with DNP-BSA $(1 \mu \mathrm{g} / \mathrm{ml})$ for $30 \mathrm{~min}$ at $37^{\circ} \mathrm{C}$. Aliquots of the cellular supernatant $(15 \mu \mathrm{l})$ were transferred to 96 well plates and incubated with $60 \mu \mathrm{l}$ of substrate (1 mM p-nitrophenyl-N-acetyl- $\beta$-D-glucosaminide in citrate $0.05 \mathrm{M}, \mathrm{pH} 4.5$ ) for $60 \mathrm{~min}$ at $37^{\circ} \mathrm{C}$. The cells were lysed with $0.1 \%$ Triton $\mathrm{X}-100$ before removing the supernatant to measure the total $\beta$-hexosaminidase activity. The reaction was stopped by adding $150 \mu \mathrm{l}$ of $\mathrm{Na}_{2} \mathrm{CO}_{3} \mathrm{NaHCO}_{3}$ buffer $0.1 \mathrm{M}, \mathrm{pH} 10$. The absorbance at $405 \mathrm{~nm}$ was measured with a microplate reader (Themo Labsystems). The results were presented as the percentage of total $\beta$-hexosaminidase content of the cells determined by cell lysis with $0.1 \%$ Triton $\mathrm{X}-100$.

$$
\begin{aligned}
& \% \text { Degranulation }=O D_{\text {supernatant }} /\left(\mathrm{OD}_{\text {supernatant }}+\mathrm{OD}_{\text {triton }}\right. \\
& \mathrm{x}-100) \times 100
\end{aligned}
$$

\section{Westem blotting}

Total cell lysates were plated at $3 \times 10^{7}$ cells $/ \mathrm{ml}$ and treated with fucoxanthin $(0.1,1$, and $10 \mu \mathrm{g} / \mathrm{ml})$ and DNP-BSA $(0.01$ $\mu \mathrm{g} / \mathrm{ml}$ ) for $15 \mathrm{~min}$ and then harvested and lysed in a lysis buffer containing $20 \mathrm{mM}$ Tris, $\mathrm{pH} 7.6,150 \mathrm{mM} \mathrm{NaCl}$, and $1 \%$ Triton X-100 with a protease inhibitor cocktail. Protein con- tents were measured using a protein assay kit (Bio-Rad). Samples were diluted with $1 \times$ lysis buffer containing $1 \% \beta$ -mercaptoethanol. Equal amounts of cellular protein $(50 \mu \mathrm{g})$ were resolved by $10 \%$ SDS-PAGE and transferred onto nitrocellulose membranes. After blocking, membranes were incubated with the target antibody and then with horseradish peroxidase-conjugated secondary antibody to IgG. Immunoreactive proteins were visualized using the ECL Western blot detection system. The protein level was compared to a loading control, such as $\beta$-actin or non-phosphorylated protein.

\section{Subcellular fractionation}

Cytosolic and nuclear extracts were prepared. In brief, RBL-2H3 cells $\left(5 \times 10^{6}\right.$ cells $\left./ \mathrm{ml}\right)$ were plated into $100 \mathrm{~mm}$ dishes and treated with fucoxanthin $(0.1,1$, and $10 \mu \mathrm{g} / \mathrm{ml})$ and IgE/DNP-BSA $(0.01 \mu \mathrm{g} / \mathrm{ml})$ for $4 \mathrm{~h}$. The harvested cells were resuspended in $0.2 \mathrm{ml}$ of buffer A (10 mM HEPES at pH 7.5, $1.5 \mathrm{mM} \mathrm{MgCl}_{2}, 10 \mathrm{mM} \mathrm{KCl}, 1 \mathrm{mM}$ DDT, 0.1\% NP-40, 0.2 $\mathrm{mM}$ PMSF). The cells were lysed on ice for $15 \mathrm{~min}$, and centrifuged $\left(5,000 \mathrm{~g}, 5 \mathrm{~min}, 4^{\circ} \mathrm{C}\right)$. The supernatant was collected as cytosolic extracts. The nucleic pellet was washed with buffer A lacking NP-40, and resuspended in $25 \mu \mathrm{l}$ of buffer C (20 mM HEPES, pH 7.5, 25\% glycerol, $0.42 \mathrm{M}$ $\mathrm{NaCl}, 0.2$ mM EDTA, $1.5 \mathrm{mM} \mathrm{MgCl} 2,1 \mathrm{mM}$ DDT, $0.2 \mathrm{mM}$ PMSF). After incubation on ice for $30 \mathrm{~min}$, nuclear debris was spin down $\left(13,000 \mathrm{~g}, 10 \mathrm{~min}, 4^{\circ} \mathrm{C}\right)$. The supernatant was collected as nuclear extracts. The protein concentration was measured using a protein assay kit (Bio-Rad).

\section{Statistical analyses}

Each experiment was repeated three or four times, and the results of a representative experiment are shown. The results are expressed as the means \pm SEM and were compared using Student's $t$-test. A statistical probability of $p<0.05$ was considered significant $\# p<0.05$, \#\# $p<0.01, * p<0.05$, and $* *$ $p<0.01)$.

\section{Results and Discussion}

Traditional medicines isolated from natural products often have positive effects in the prevention and healing of various immune disorders, such as allergy and atopic inflammation. 
In this study, the fucoxanthin (95\% purity level) fraction of Eisenia bicyclis showed potential anti-allergic effects by decreasing $\beta$-hexosaminidase release in mast cells.

Mast cells are primary effector cells involved in the allergic or immediate hypersensitivity responses (Theoharides and Kalogeromitros, 2006). The antigen crosslinking of the IgEFceRI complexes through the aggregation of IgE and FceRI on mast cells results in the release of $\beta$-hexosaminidase, which is a marker of mast cell degranulation. The release of $\beta$ -hexosaminidase and histamines also causes the production of proinflammatory cytokines, such as IL-4, IL-6, and TNF$a$, which can potentiate inflammatory immune responses through the subsequent induction of other atopic inflammatory mediators. Thus, the modulation of this initial process is considered a rational approach for regulating the early phase of allergic responses (Gilfillan and Tkaczyk, 2006; Theoharides and Kalogeromitros, 2006). Rat mast cell line RBL-2H3 cells were used to determine the effect of fucoxanthin on the secretion of $\beta$-hexosaminidase. Initially, we measured the cytotoxicity of fucoxanthin on RBL-2H3 cells using the XTT assay. Fucoxanthin at concentrations ranging from $0.1-10 \mu \mathrm{g} / \mathrm{ml}$ did not significantly affect the cytotoxicity in $24 \mathrm{~h}$ (Fig. 2A). Thus, we treated DNP-IgE-sensitized RBL-2H3 cells with fucoxanthin ranging from $0.1-10 \mu \mathrm{g} / \mathrm{ml}$ in subsequent experiments. Fucoxanthin significantly suppressed the DNP-BSA induced $\beta$-hexosaminidase secretion in IgE-sensitized RBL$2 \mathrm{H} 3$ cells at 1 and $10 \mu \mathrm{g} / \mathrm{ml}$ and the effects are dose-dependent (Fig. 2B). Ketotifen fumarate, an anti-allergic drug, also decreased the $\beta$-hexosaminidase secretion. The results showed that fucoxanthin significantly inhibited antigen-induced mast cell degranulation.

Atopic dermatitis is characterized by allergic skin inflammation. Pathological changes in atopic skin are observed as epidermal thickening and marked infiltration of inflammatory cells (Soter, 1989). Here, we evaluated the effects of fucoxanthin on the allergic skin diseases using the kinetic proliferation and the regulation of NO production in human keratinocytes (HaCaT) and mouse fibroblast (NIH3T3) cells (Park et al., 2010), but fucoxanthin has no significant effects (Fig. 3 and 4) in both of cells.

We subsequently evaluated the related mechanisms of fucoxanthin on degranulation including $N F-\kappa B$ activation
A

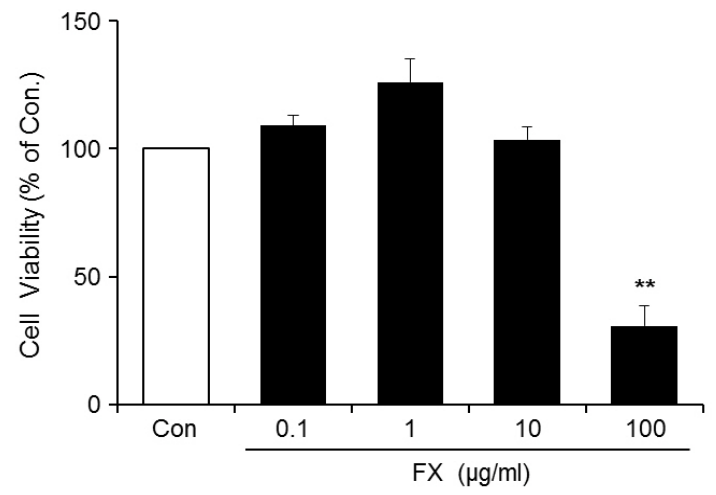

B

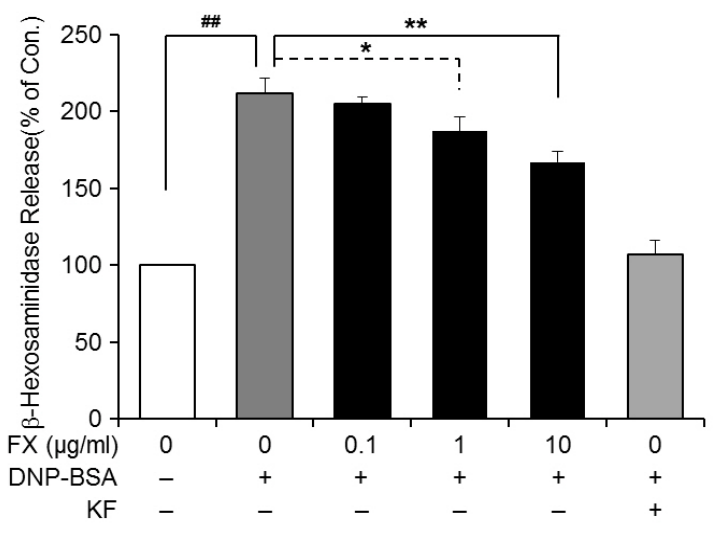

Fig. 2. The effects of fucoxanthin for cell viability and antigeninduced $\beta$-hexosaminidase in RBL-2H3 cells. (A) The cells were treated with various concentration of fucoxanthin for 24 h. Cell viability was assessed using XTT assay. Absorbance was measure data at $450 \mathrm{~nm}$ and $650 \mathrm{~nm}$. (B) The cells were sensitized by overnight incubation with $1 \mu \mathrm{g} / \mathrm{ml}$ of DNPspecific IgE in medium. These DNP-IgE-sensitized RBL-2H3 cells were pre-incubated with various concentration of fucoxanthin (FX) for $30 \mathrm{~min}$ and then incubated with antigen (IgE/DNP-BSA) for $15 \mathrm{~min}$ in order to measure the release of $\beta$-hexosaminidase. Each bar shows the means $\pm \mathrm{SEM}$ of four independent experiments. ${ }^{\#} P<0.01$ : significantly different from control group, ${ }^{* *} P<0.01,{ }^{*} P<0.05$ : significantly different from $\mathrm{IgE} / \mathrm{DNP}-\mathrm{BSA}$ alone. KF: ketotifen fumarate at $100 \mu \mathrm{M}$.

and the phosphorylation of MAPKs. We detected the inhibitory effects of fucoxanthin on IgE/DNP-BSA-induced nuclear translocation of NF-kB (p65). Increased expression of NF- $\mathrm{k}$ $B$ (p65) was observed in the nucleus after treatment with fucoxanthin in IgE/DNP-BSA-stimulated RBL-2H3 cells for $4 \mathrm{~h}$ (Fig. 5). The relative intensity of NF-kB (p65) translocation in the nucleus was increased significantly in $\mathrm{IgE} /$ DNP-BSA-stimulated RBL-2H3 cells compared with the no 
A

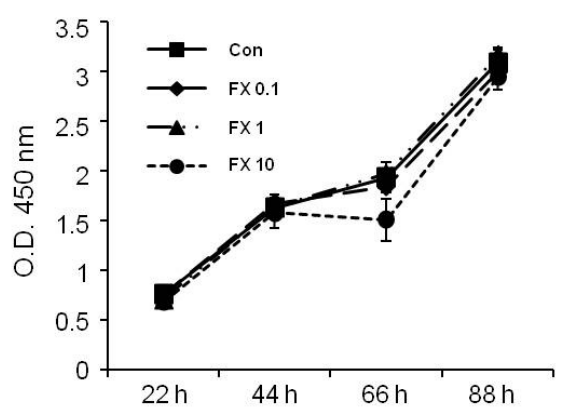

B

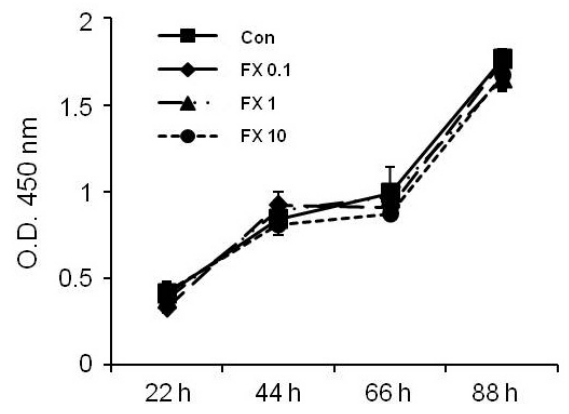

Fig. 3. The effects of fucoxanthin on proliferation in keratinocytes (HaCaT) and fibroblast (NIH3T3) cells. (A) HaCaT and (B) NIH3T3 cells were treated with fucoxantin (FX) for 22, 44, 66, 88 hrs. The proliferations of cells were assessed by XTT assay. Cell proliferations were represented by the percentage of control. The results are mean $\pm \mathrm{SEM}$ of quintuplicates from a representative experiment.

A

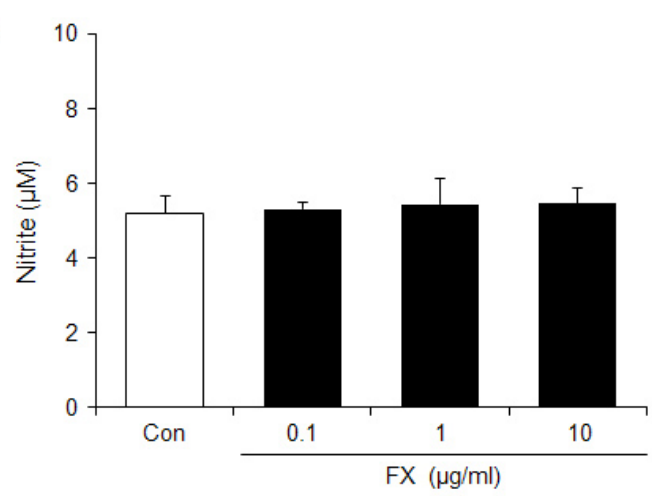

B

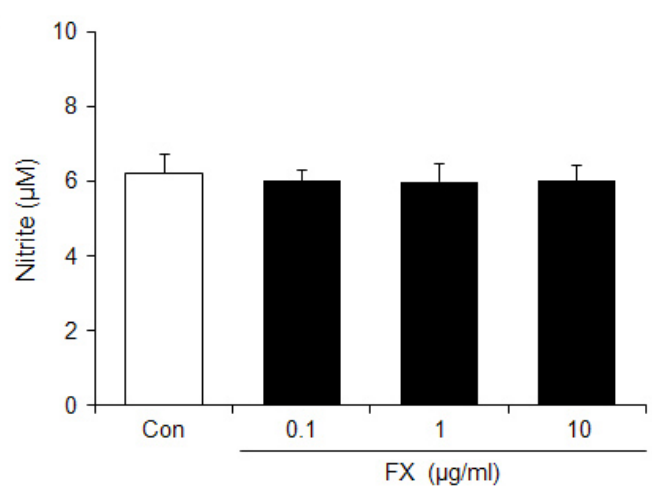

Fig. 4. The effects of the fucoxantin (FX) on the production of NO in (A) HaCaT keratinocytes and (B) NIH3T3 fibroblast cells. These results are means $\pm \mathrm{SEM}$ of quintuplicates from a representative experiment.

antigen treatments. In contrast, the relative intensity of NF- $\mathrm{K}$ B (p65) translocation in the nucleus was decreased considerably, to the control basal level, after the addition of $10 \mu \mathrm{g} /$ $\mathrm{ml}$ fucoxanthin. These data demonstrate that fucoxanthin attenuated NF- $\mathrm{KB}$ activation and might affect the degranulation of histamine in mast cells.

$\mathrm{NF}-\mathrm{kB}$ is a key transcription factor that regulates the expression of genes involved in immune and inflammatory responses that require inflammatory cytokine production. NF- $\mathrm{KB}$ translocation and the MAPKs pathway are regarded as important processes in the regulation of the innate and acquired immune responses and chronic allergic inflammation (Karin and Lin, 2002; Barnes, 2008). NF-kB is also a critical transcription factor that regulates Th2 cell differentiation and Th2-dependent airway inflammation in asthma (Yang et al., 1998). Increased NF-kB activity has been

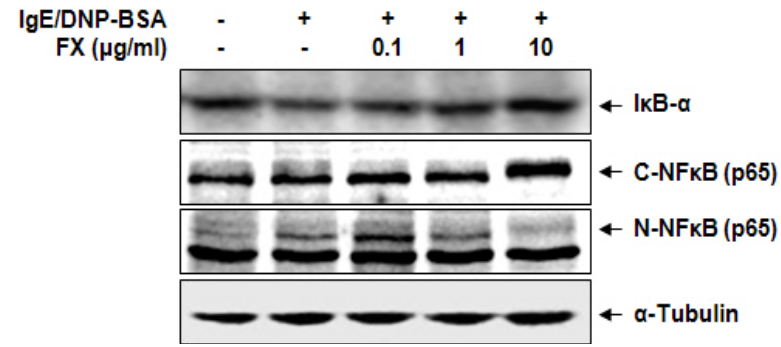

Fig. 5. Effects of fucoxantin on NF-kB activation in IgE/DNPBSA-stimulated RBL-2H3 mast cells. The cells were sensitized by overnight incubation with $1 \mu \mathrm{g} / \mathrm{ml}$ of DNP-specific IgE in medium. This DNP-IgE-sensitized RBL-2H3 cells were preincubated with various concentration of fucoxanthin (FX, 0.1, 1 , and $10 \mu \mathrm{g} / \mathrm{ml}$ ) for $30 \mathrm{~min}$ and then incubated with antigen (IgE/DNP-BSA) for $15 \mathrm{~min}$. After isolation of cytosolic (C-) and nuclear (N-) fraction, the translocation of NF- $\mathrm{kB}(\mathrm{p} 65)$ was assessed by Western blotting described in methods respectively. 


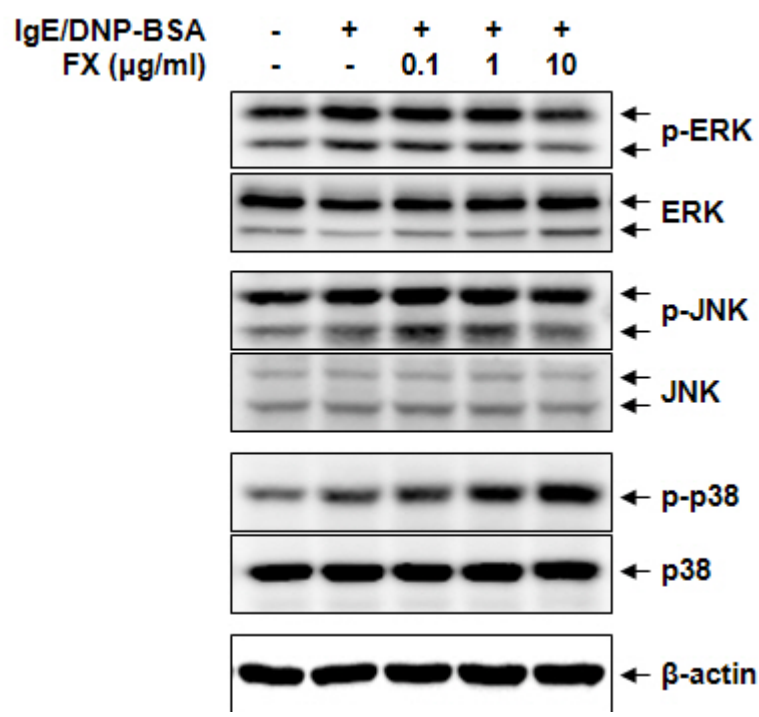

Fig. 6. Effects of fucoxantin on phosphorylations of MAPKs in IgE/DNP-BSA-stimulated RBL-2H3 mast cells. The cells were sensitized by overnight incubation with $1 \mu \mathrm{g} / \mathrm{ml}$ of DNPspecific IgE in medium. This DNP-IgE-sensitized RBL-2H3 cells were pre-incubated with various concentration of fucoxanthin (FX, 0.1, 1, and $10 \mu \mathrm{g} / \mathrm{ml}$ ) for $30 \mathrm{~min}$ and then incubated with antigen (DNP-BSA) for $15 \mathrm{~min}$. The phosphorylations of p38 MAP kinase such as p38, JNK and ERK were assessed by Western blotting described in methods.

reported in asthma, an allergic disease, and the inhibition of NF- $\kappa B$ activity decreased asthma (Barnes, 2008). Thus, we suggest that fucoxanthin could have an anti-allergic effect based on the decrease in activated NF- $\kappa B$ it causes.

Conventional MAP kinases are classified into three families: the c-Jun N-terminal kinases (JNKs), the p38 MAP kinases, and the extracellular signal-regulated kinases (ERKs). Intracellular signal transduction, including the phosphorylation of p38 MAPK, is subsequently followed by NF-kB translocation, leading to the production of cytokines and chemokines.

We also showed that fucoxanthin significantly suppressed the IgE/DNP-BSA-activated phosphorylation of ERK and JNK but not $\mathrm{p} 38$ in RBL-2H3 mast cells (Fig. 6). It has been reported that MAPK activation can activate transcription factors that result in the expression of IL-4, IL-5, and IL-13 in human $\mathrm{T}$ cells in response to antigen exposure in allergic disease (Barnes, 2008). Recently, Lee et al. (2012) reported that the glycoprotein isolated from Cudrania tricuspidata inhibits release of $\beta$-hexosaminidase via down regulation of
MAPK/NF- $k \mathrm{~B}$ on the stage of mast cell degranulation.

We found here that fucoxanthin may exert inhibitory effects on the antigen-induced degranulation by suppressing the transcription of NF- $\mathrm{KB}$ and the activation of ERK-JNK but not of p38 in signaling pathways. From these results, we suggest that fucoxanthin might be useful as a therapeutic agent for treating various forms of allergic inflammation, including asthma and atopic dermatitis.

\section{Literature Cited}

Barnes, P.J. 2008. Role of GATA-3 in allergic diseases. Curr. Mol. Med. 8:330-334.

Ding, A.H., C.F. Nathan and D.J. Stuehr. 1988. Release of reactive nitrogen intermediates and reactive oxygen intermediates from mouse peritoneal macrophages. Comparison of activating cytokines and evidence for independent production. J. Immunol. 141:2407-2412.

Gilfillan, A.M. and C. Tkaczyk. 2006. Integrated signaling pathways for mast-cell activation. Nat. Rev. Immunol. 6: 218-230.

Hu, T., D. Liu, Y. Chen, J. Wu and S. Wang. 2010. Antioxidant activity of sulfated polysaccharide fractions extracted from Undaria pinnitafida in vitro. Int. J. Biol. Macromol. 46: 193-198.

Huang, F., K. Yamaki, X. Tong, L. Fu, R. Zhang, Y. Cai, R. Yanagisawa, K. Inoue, H. Takano and S. Yoshino. 2008. Inhibition of the antigen-induced activation of RBL-2H3 cells by sinomenine. Int. Immunopharmacol. 8:502-507.

Joe, M.J., S.N. Kim, H.Y. Choi, W.S. Shin, G.M. Park, D.W. Kang and Y.K. Kim. 2006. The inhibitory effects of eckol and dieckol from Ecklonia stolonifera on the expression of matrix metalloproteinase-1 in human dermal fibroblasts. Biol. Pharm. Bull. 29:1735-1739.

Kang, K., H.J. Hwang, D.H. Hong, Y. Park, S.H. Kim, B.H. Lee and H.C. Shin. 2004. Antioxidant and antiinflammatory activities of ventol, a phlorotannin-rich natural agent derived from Ecklonia cava, and its effect on proteoglycan degradation in cartilage explant culture. Res. Commun. Mol. Pathol. Pharmacol. 115-116:77-95.

Karin, M. and A. Lin. 2002. NF-kB at the crossroads of life and death. Nat. Immunol. 3:221-227.

Kim, S.M., Y.F. Shang and B.H. Um. 2011. A preparative method for isolation of fucoxanthin from Eisenia bicyclis by 
centrifugal partition chromatography. Phytochem. Anal. 22 (4):322-329.

Lee, J., S.J. Lee and K.T. Lim. 2012. CTB glycoprotein (75 $\mathrm{kDa}$ ) inhibits IgE releasing, TNF-a and IL-6 expressed by bisphenol A in vivo and in vitro. Food Chem. Toxicol. 50 (6):2109-2117.

Matsuda, H., Q. Wang, K. Matsuhira, S. Nakamura, D. Yuan and M. Yoshikawa. 2008. Inhibitory effects of thunberginols $\mathrm{A}$ and $\mathrm{B}$ isolated from Hydrangeae Dulcis Folium on mRNA expression of cytokines and on activation of activator protein1 in RBL-2H3 cells. Phytomedicine 15:177-184.

Namkoong, S., S.C. Kang, H. Do, K.H. Jang, S.A. Jang, M.G. Choung and E.H. Sohn. 2011. Immunomodulatory effects of supplementation with extracts from the marine brown alga Eisenia bicyclis on macrophages. J. Korean Plant Res. 24(3): 298-303.

Naal, R.M., J. Tabb, D. Holowka and B. Baird. 2004. In situ measurement of degranulation as a biosensor based on RBL2H3 mast cells. Biosens Bioelectron. 20(4):791-796.
Park, H.J., D.H. Jung, H. Joo, N.S. Kang, S.A. Jang, J.G. Lee and E.H. Sohn. 2010. The comparative study of anti-allergic and anti-inflammatory effects by fermented red ginseng and red ginseng. J. Korean Plant Res. 23(5): 393-485 (in Korean).

Peng, J., J.P. Yuan, C.F. Wu and J.H. Wang. 2011. Fucoxanthin, a marine carotenoid present in brown seaweeds and diatoms: metabolism and bioactivities relevant to human health. Mar. Drugs. 9(10):1806-1828.

Soter, N.A. 1989. Morphology of atopic eczema. Allergy 44 (Suppl 9):16-19.

Theoharides, T.C. and D. Kalogeromitros. 2006. The critical role of mast cells in allergy and inflammation. Ann. NY Acad. Sci. 1088:78-99.

Yang, L., L. Cohn, D.H. Zhang, R. Homer, A. Ray and P. Ray. 1998. Essential role of nuclear factor $B$ in the induction of eosinophilia in allergic airway inflammation. J. Exp. Med. 188:1739-1750.

(Received 30 May 2012 ; Revised 15 June 2012 ; Accepted 25 June 2012) 